\title{
The Fire Danger Rating Index "FMA" as Control of Remote Sensoring System
}

\author{
Ernandes Aparecido Saraiva ${ }^{1}$, Horácio Tertuliano ${ }^{2}$, Ronaldo Viana Soares ${ }^{1}$, Antônio Carlos Batista ${ }^{1}$ and Ana \\ Maria Gomes ${ }^{3}$ \\ 1. Department of Forestry, Federal University of Parana State, Curitiba 80210-170, Brazil \\ 2. Department of Electrical, Federal University of Parana State, Curitiba 81531-990, Brazil \\ 3. Meteorological Research Institute, São Paulo State University, Bauru 17015-970, Brazil
}

\begin{abstract}
Recent remote monitoring surveys of smoke produced by burning and forest fires using weather radar equipment showed excellent preliminary results, but their progress is hindered due to the high operating cost of radar systems. The fire danger rating index is a good indicator of the event occurrence probability, what contributes to the monitoring areas and adds value to the alert degree information. The application of FMA fire danger index "Formula de Monte Alegre" for areas in radar coverage radius of the S-band weather radar operated by the Meteorological Research Institute, IPMet, São Paulo State University, efficiently optimize the use of the radar equipment, significantly reduce operational costs, enable new research and promise results which have already reduced the average response time between ignition and detection for less than 5 minutes. It reduces more than 50\% response time considered optimal for conventional detection systems. Thus, the "FMA" values act as a trigger (on-off) in the remote monitoring system of forest fires, optimizing its use at low cost, avoiding the possible stress of equipment and enabling the advance of research monitoring, detection of burnings and forest fires using weather radar.
\end{abstract}

Key words: Fire danger index, remote sensing, fire detection, weather radar.

\section{Introduction}

The efficiency on forest fire control is directly related to the rapidness on the occurrences detection and localization, which significantly minimizes the potential of damages. The objective of this research is to use the FMA fire danger index as tool auxiliar for the operations of the weather radar and comprove your capacity to monitor and detect "non meteorological targets", for example, the smoke produced sugar cane burnings and, by similarity, forest fires.

There are several difficulties and limitations in the most widely method used for monitoring and detection of forest fires - the observation towers. The high cost of installation and operation is one of the handicaps of the system. When the number of towers is not sufficient, some fires are detected as the intensity is already high

Corresponding author: Ernandes Aparecido Saraiva, Ph.D., researcher fields: forest fire detection and remote sensing. and the suppression more difficult.

Trying to improve monitoring and detection of forest fires, this research used the remote sensing technology to detect events related to fire. The biomass combustion process produces large amounts of smoke, an excellent target which can be detected by remote monitoring of various electromagnetic wavelengths. The particles and water vapor that constitute the smoke is an excellent electromagnetic spreader. The application of FMA fire danger index "Formula de Monte Alegre" for areas in radar coverage radius of the S-band weather radar operated by the Meteorological Research Institute, IPMet, São Paulo State University, UNESP, located in Bauru, central region of the state of São Paulo, Brazil, efficiently optimize the use of the radar equipment.

Combining the weather radar idleness during the dry season and the fire occurrence danger degree in the same period, an experimental model of fire detection 
was built. The model was initially tested on the frequent and programmed sugar cane harvesting burnings in the central region of São Paulo State, which is monitored by a weather radar equipment "S-band Doppler". It is operated by the Meteorological Research Institute, UNESP, which located at the Bauru county. In the same region covered by the radar system, there are large plantations of pine and eucalyptus owned by Duratex, which were monitored during high fire danger indices in the second phase of the experiment.

\section{Material and Methods}

The Radar (Radio Detection and Ranging) is considered as an active element. It illuminates the target with a microwave beam and identifies this target through the detection of the energy portion reflected back (Fig. 1). The choice of the operation wavelength $(\lambda)$ is primarily defined according to the type, size and distribution of the targets investigated or detected [1-4].

\subsection{Detection Capability}

The weather radar was conceived to act in the area of meteorology, but with the continuous technology development, it received several improvements in the digitalization of the acquisition and signal processing, sensibility and detection capability, as well as in the mitigation of the errors associated to the measurements.

Its full technological capacity is not used in the everyday operation. Considering that a drizzlehas level radar reflectivity of about $10 \mathrm{dBz}$ (decibels of reflectivity), and its detection range can start in the order the minus $30 \mathrm{dBz}$, the difference is huge when talking about the logarithmic scale [1].

Meteorological research centers and operations that use weather radar system have long observed detections not associated with rain, which does not directly influence their activities. This fact has led to researches that confirm the radar capacity to operate

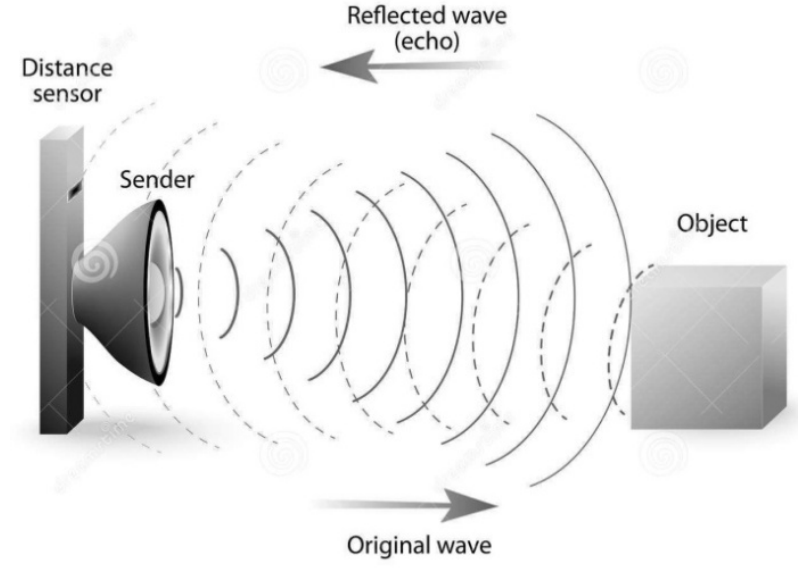

Fig. 1 Microwave detection concept.

with high sensitivity tasks and detect the so-called "non-meteorological targets" such as wind speed profile, gust fronts, particles in suspension, birds flight, cluster of insects and smoke [5-9].

\subsection{Fire Detection}

The detection of a fire occurs indirectly since it is detects not the fire flame or the heat but the smoke produced by the biomass burning. Initially, a high sensitivity parameter task is programmed.

Usually the weather radar monitors rain from the top to the base of the clouds. To forest fire detection, the radar monitoring occurs from the soil surface to up in the sky, where begins the formation of the cloud of smoke.

When forest fuel or biomass burns, the released smoke rises and crosses the microwave beam of the radar, backscattering incident energy, resulting in the event detection (Fig. 2). It is important to take into account the effect of the earth's curvature in determining the elevation of the antenna in executing the tasks and the analysis of detected echoes.

The purpose of this study was to detect smoke originated from biomass burning as close to the ground as possible. This is important because as it moves away from the radar location, the average height of the microwave beam increases in relation to the ground.

As the fire starts in the soil surface and the quicker it is detected the easier it is controled. The microwave 


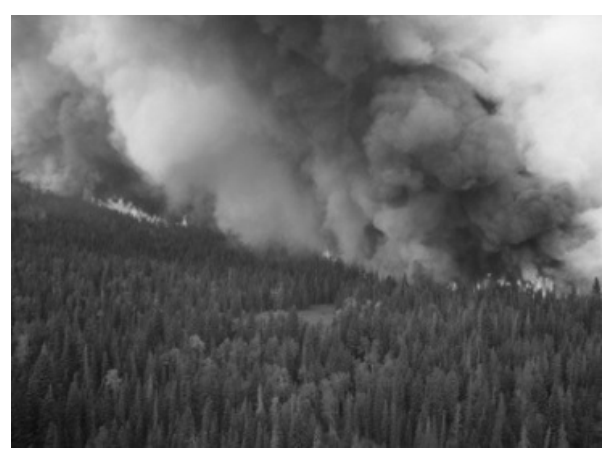

Fig. 2 Vegetation fires release smoke and intercept the radar beam.

beam must cross the monitoring area as low as possible, but not too low to avoid touching the ground and reflecting "echoes of ground", polluting the image with noises.

The study area should be away from the radar for not being influenced by the effects of antenna radiation side lobes that impair detection efficiency. In a distance of around $50 \mathrm{~km}$ from the radar, the height of the microwave beam emitted from the antenna to elevations between 0.3 degrees and 2.0 degrees crossed the study area up to 2,000 meters height, which is ideal for smoke detection.

Interest areas are monitored only when the values of the fire danger rating index "FMA" are high and very high. Thus, the "FMA" values act as a trigger (on-off) in the remote monitoring system of forest fires, optimizing its use at low cost and avoiding the possible stress of equipment (Fig. 3).

Only the values of FMA is high and very high, running task with high sensitivity and temporal sampling of 7.5 minutes, the S-band Doppler weather radar monitored the 12 burning events in the sugar cane plots. All the burnings were accompanied in situ, and with the time synchronized to the radar time system, the exact ignition time and the events duration were recorded.

The radar data were treated with the TITAN software, developed by researchers at National Center for Atmospheric Research (NCAR) in Boulder, United States, which uses to forecast the displacement of storms based on the "centroid" methodology [10].

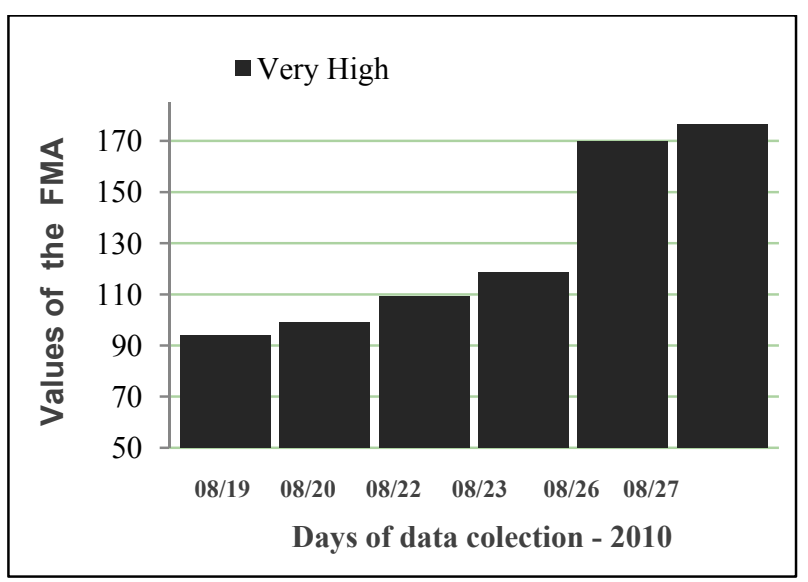

Fig. 3 Values of the FMA in days of data colection

The images used are Cartesian products called Constant Altitude Plan Position Indicators (CAPPIs) with the viewing plane at constant average height of $1.5 \mathrm{~km}$ from the ground.

\section{Results and Discussion}

Data from the burned plots, including time of ignition and detection, duration of fire and response time between ignition and detection are showed in Table 1.

The response time ranged from 2 minutes to 9 minutes with an average of 4.67 minutes, reducing $68.9 \%$ the response time which was considered ideal in the conventional detection systems [11].

The site 9 before ignition and without radar echoes (22:00 GMT) is showed in Fig. 4.

Fig. 5 shows the site 9 with the first radar echoes, 5 minutes after ignition (22:02 GMT). Figs. 6 and 7 show the site 9 with the radar echoes during burning and the Figs. 8 and 9 show the site 9 at 22:37 and 22:45 GMT, 5 minutes and 13 minutes after the end of burning and without radar echoes in monitoring area.

Table 1 Summary of monitored and detected events.

\begin{tabular}{lllll}
\hline \multirow{2}{*}{ Site } & \multicolumn{2}{c}{$\begin{array}{c}\text { Schedule of burnings } \\
\text { (GMT) }\end{array}$} & $\begin{array}{l}\text { Radar } \\
\text { detection }\end{array}$ & $\begin{array}{l}\text { Radar } \\
\text { response }\end{array}$ \\
\cline { 2 - 5 } & Start (hh:mm) & $\begin{array}{l}\text { End } \\
\text { (hh:mm) }\end{array}$ & $\begin{array}{l}\text { Start } \\
\text { (hh:mm) }\end{array}$ & $\begin{array}{l}\text { (mimuts) } \\
\text { (mime }\end{array}$ \\
\hline 1 & $22: 28$ & $22: 48$ & $22: 30$ & 2 \\
4 & $22: 21$ & $22: 37$ & $22: 30$ & 9 \\
9 & $22: 02$ & $22: 32$ & $22: 07$ & 5 \\
\hline
\end{tabular}




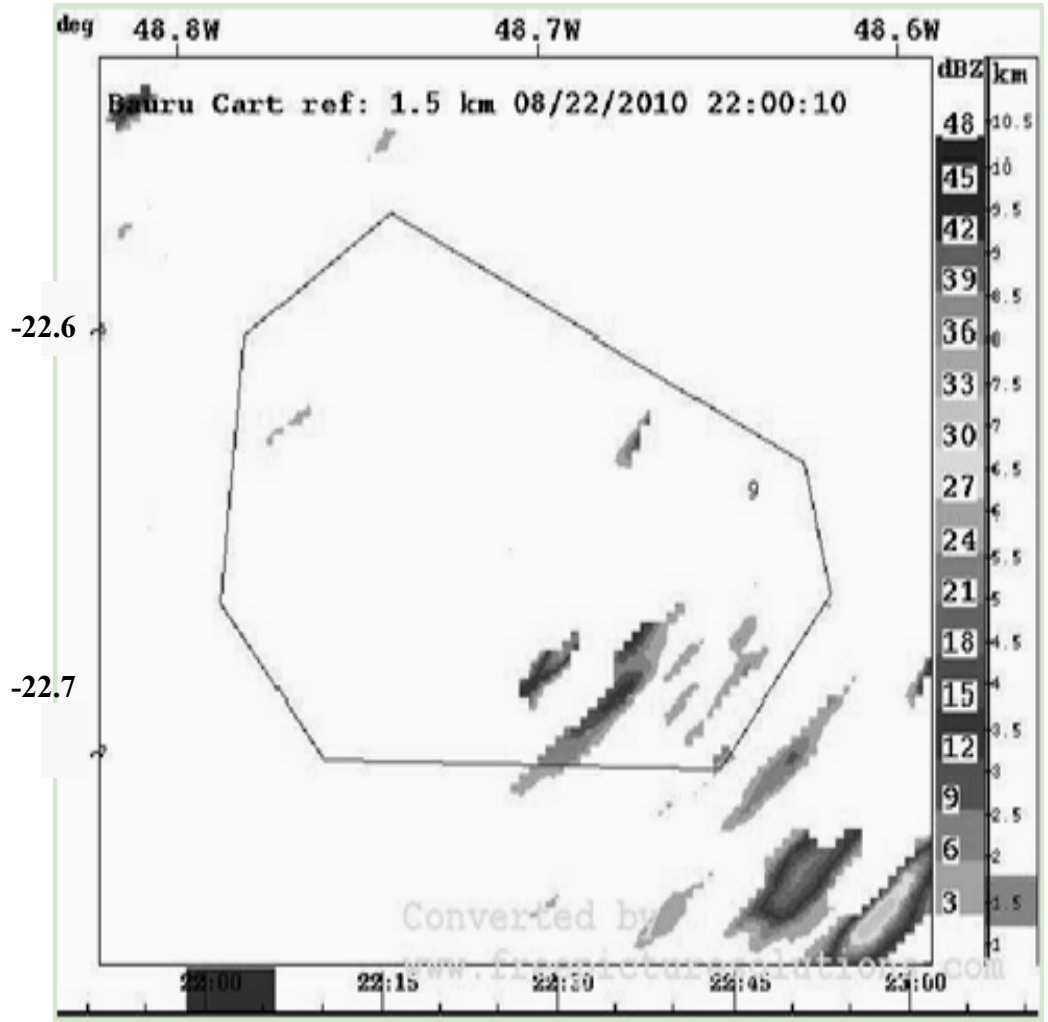

Fig. 4 Image of the study area and the monitored site 9.

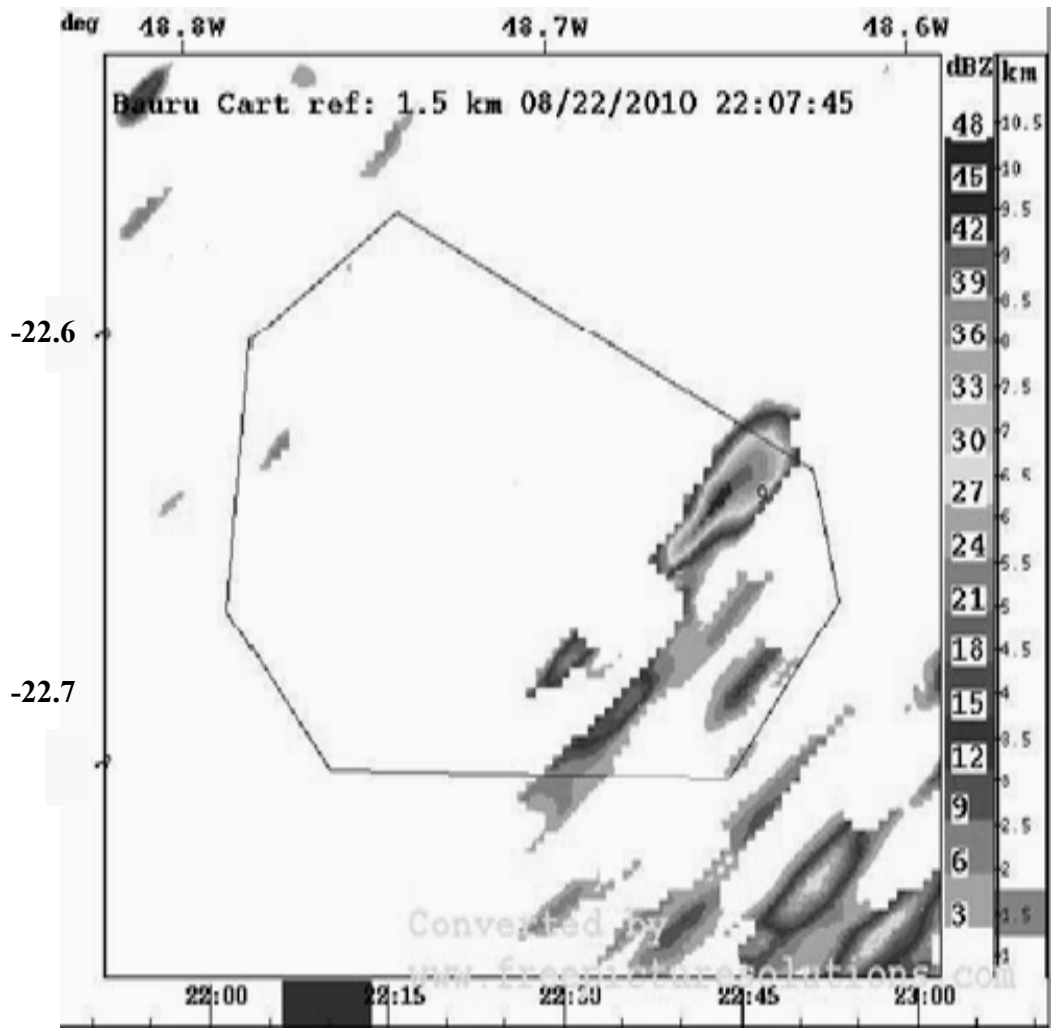

Fig. 5 Site 9 with the first radar echo of the burning. 


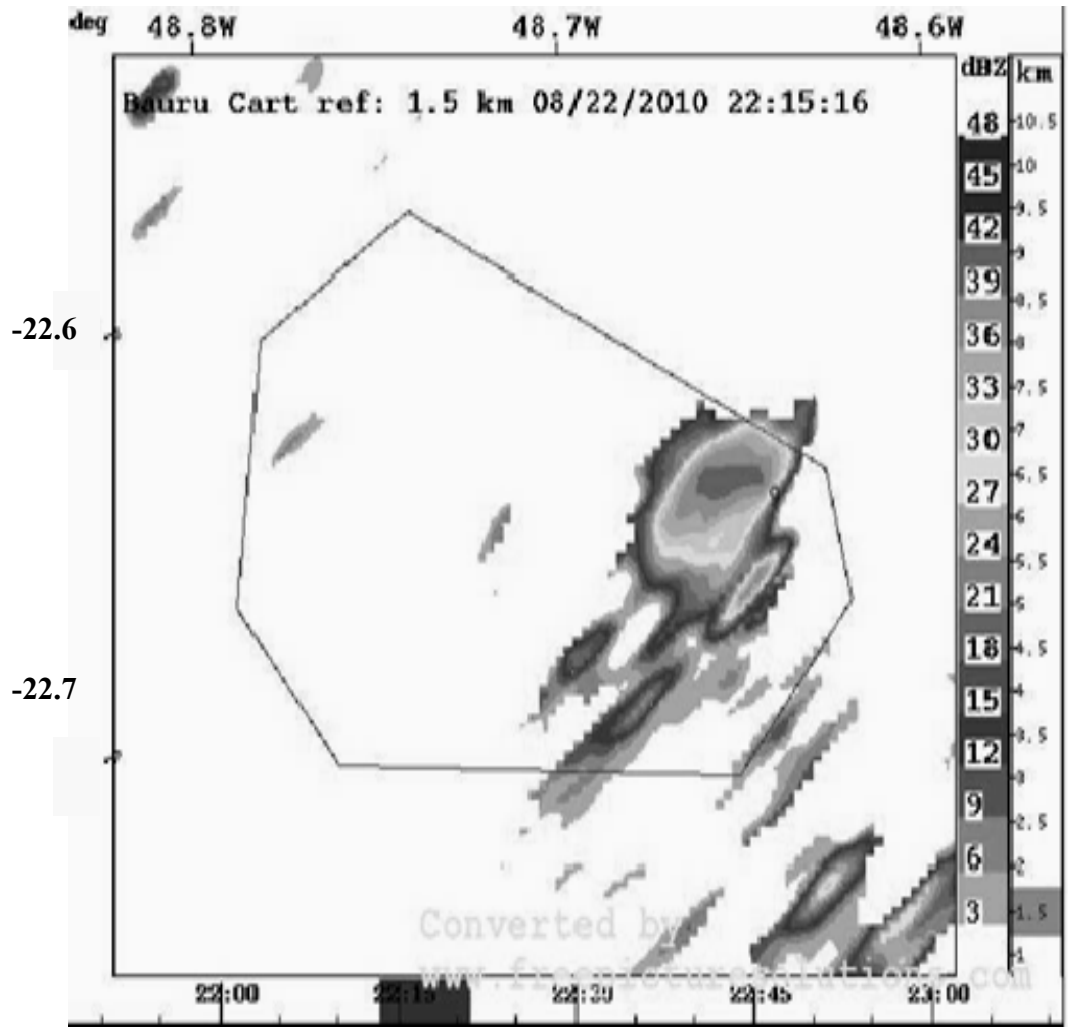

Fig. 6 Site 9 with radar echoes during the fire.

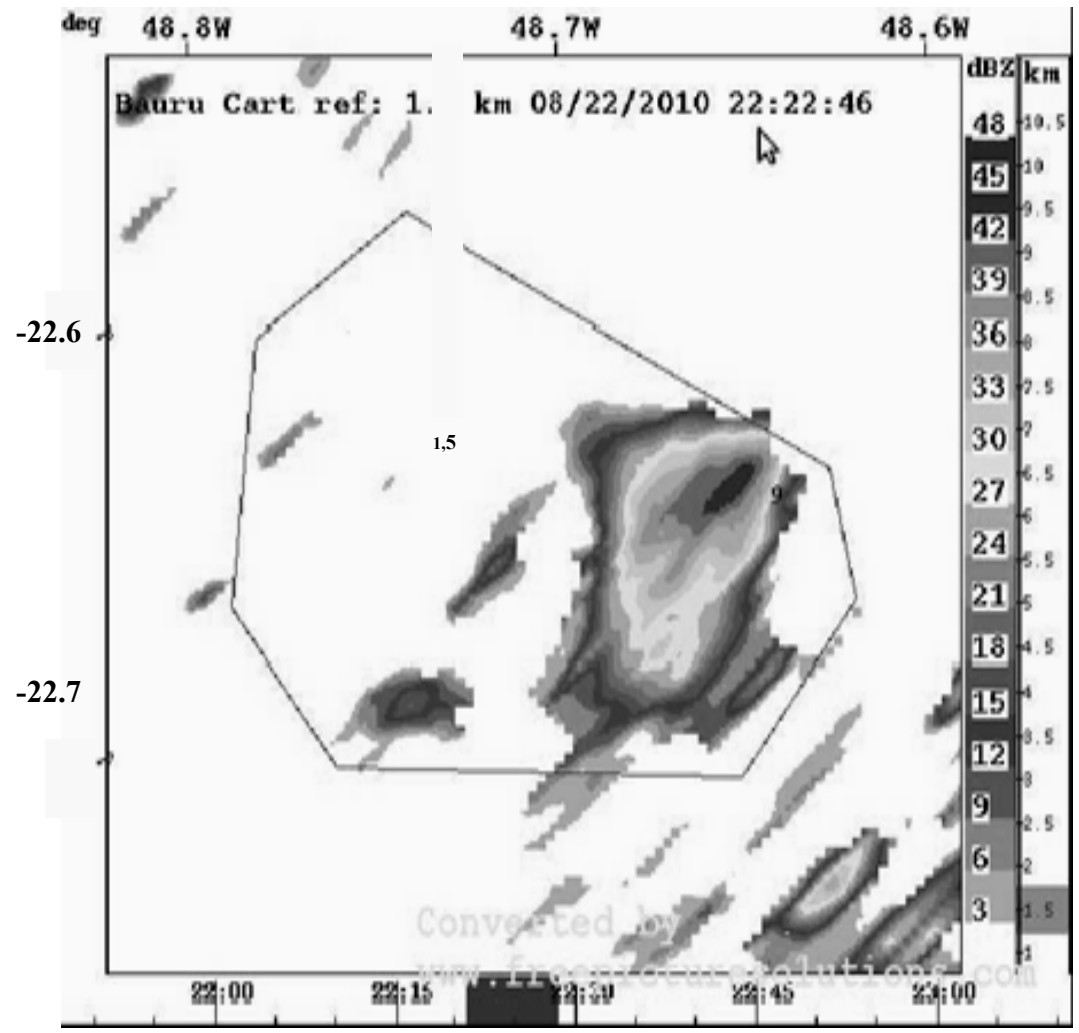

Fig. 7 Site 9 with radar echoes and fire ending. 


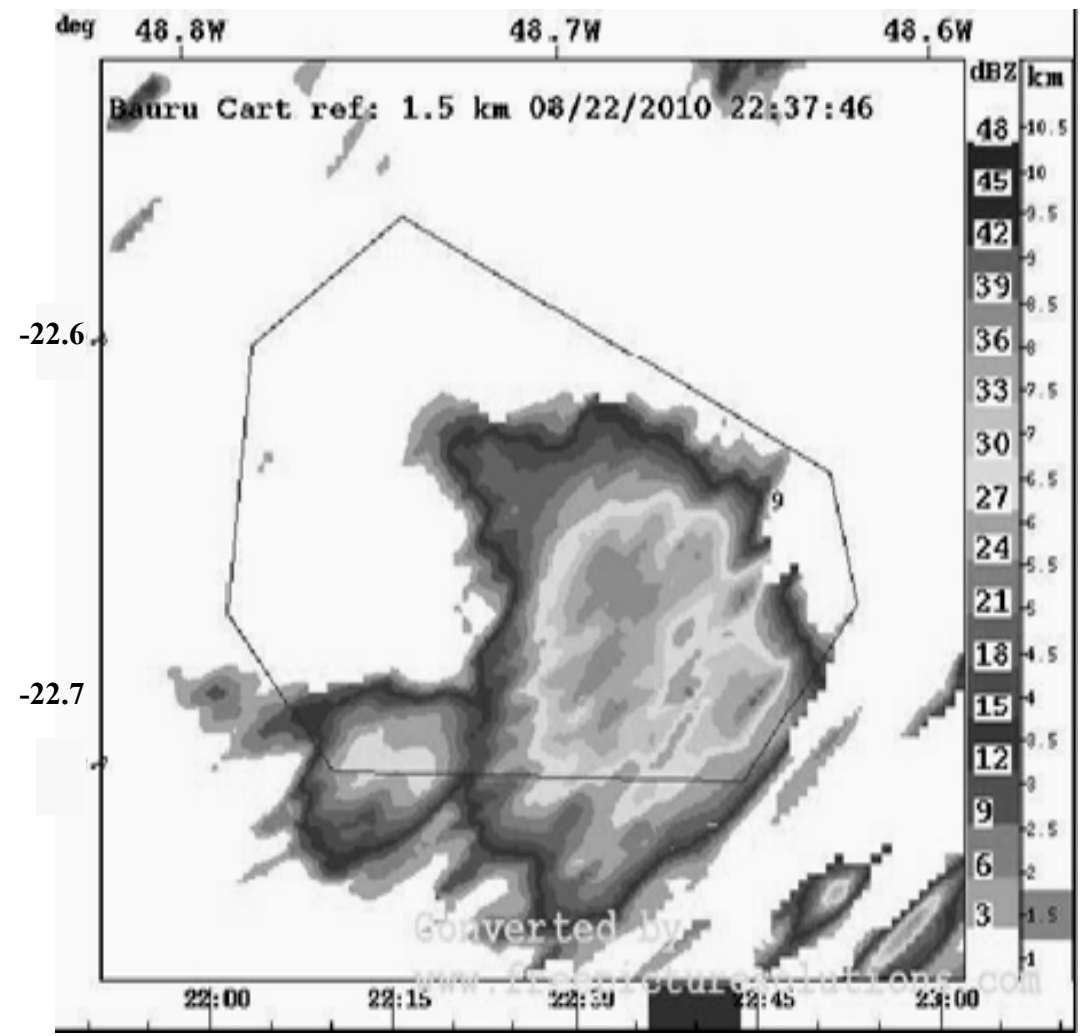

Fig. 8 Site 9 after burning and without radar echoes.

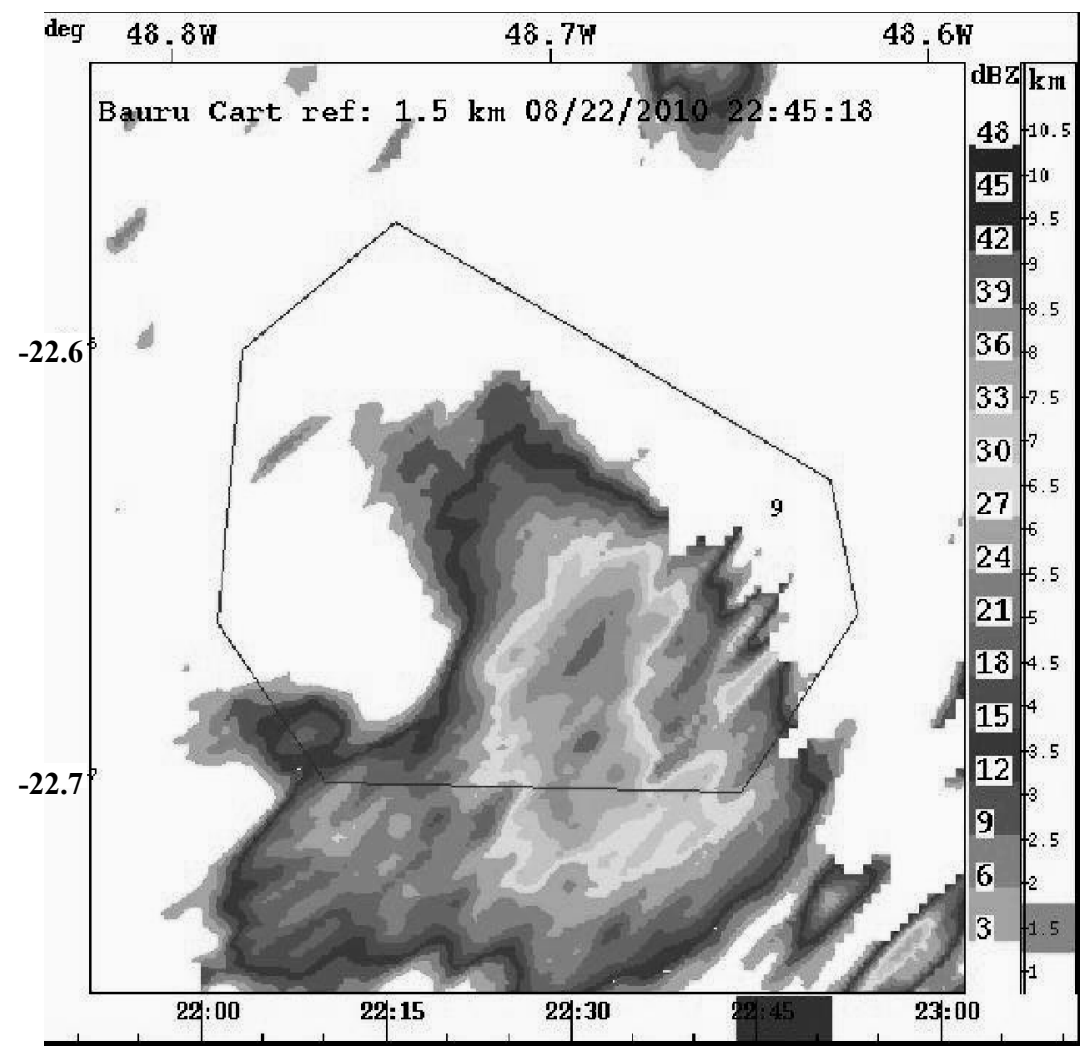

Fig. 9 After burning site 9 without smoke cloud. 
In august 2014, with the same task and temporal resolution and monitoring the reforestation areas owned by Duratex company, the weather radar detected the smoke of forest fire. The only two small fire spots detected by the company's observation towers were also detected by the radar system. Synchronizing the time from the radar and the observation tower, the radar detected the fires 6 an 8 minutes in advance, respectively.

\section{Conclusions}

The fire danger rating index FMA is excellent auxiliary tool for monitoring the weather radar of the forest fires.

The system S-band Doppler weather radar has detected all events of burning in monitored plots of sugar cane, as well as the fire occurrences detected by the observation towers in reforestation areas.

The results showed that the weather radar can be an important auxiliary tool for detecting unauthorized burning and forest fires, adding significant value to the information for decision-making in monitoring, detecting and suppressing wildfires.

The X-band radar, for example, with technical characteristics for monitoring smaller targets, combined with increased temporal resolution, could be an even better alternative to smoke detection and shorter response time.

\section{References}

[1] Doviak, R. J., Zrnic, D. S. 1992. Doppler Radar and
Weather Observations. San Diego, California: Academic Press.

[2] Lhermitte, R. 2002. Centimeter \& Millimeter Wavelength Radars in Meteorology. Miami: University Publications.

[3] Silver, S. 1949. Microwave Antenna Theory and Design. New York: McGraw Hill Book Company.

[4] Ollero, A., Dios, J. R. M., and Arrue, B. C. 1998. "Integrated Systems for Early Forest Fire Detection." In III International Conference on Forest Fire Research and 14th Conference on Fire and Forest Meteorology, 1977-1988.

[5] Banta, R. M., and Olivier, L. D. 1992. "Smoke-Column Observations from Two Forest Fire Using Doppler Lidar and Doppler Radar." Journal of Applied Meteorology 31: 1328-1349.

[6] Calheiros, R. V., and Gomes, A. M. 1999. "Wind Profiling in Clear Air: A Radar-Radiosonde Comparation." In Proceedings of the International Seminar on Advanced Weather Radar Systems, 678-687.

[7] Held, G., Lopes, F. J. S., Bassan, J. M., Cardoso, A. A., and Gomes, A. M. 2011. "Raman Lidar Monitors Emissions from Sugar Cane Fires in the State of São Paulo." Magazine of Bolivian Society of Physical 20: 24-26.

[8] Erlelens, J. S., and Venema, V. K. C. 2000. "Coherent Scattering of Microwaves by Particles: Evidence from Clouds and Smoke." In American Meteorologcal Society, 1091.

[9] Gary, L., Hufford, H., Lee, K., and Willian, S. 1998. "Use of Real-Time Multisatellite and Radar Data to Support Forest Fire Management." In Weather and Forecasting, 592.

[10] Gomes, A. M. 2007. The XAT Technique for Volumes Determination. Botucatu: Universidade Estadual Paulista-UNESP.

[11] Soares, R. V., and Batista, A. C. 2007. Forest Fires: Control, Effects and Use of Fire. Curitiba: Universidade Federal do Parana-UFPR. 